\title{
Genetic analysis of groups of mid-infrared predicted fatty acids in milk
}

\author{
S. G. Narayana, ${ }^{*}$ F. S. Schenkel, ${ }^{*}$ A. Fleming, ${ }^{* 1}$ A. Koeck, ${ }^{*}$ F. Malchiodi, ${ }^{*}$ J. Jamrozik, ${ }^{*} \dagger$ J. Johnston, $\dagger$ \\ M. Sargolzaei, ${ }^{*} \ddagger$ and F. Miglior*† \\ *Department of Animal Biosciences, Centre for Genetic Improvement of Livestock, University of Guelph, Guelph, ON, N1G 2W1, Canada \\ †Canadian Dairy Network, Guelph, ON, N1K 1E5, Canada \\ ‡Semex Alliance, Guelph, ON, N1H 6J2, Canada
}

\section{ABSTRACT}

The objective of this study was to investigate genetic variability of mid-infrared predicted fatty acid groups in Canadian Holstein cattle. Genetic parameters were estimated for 5 groups of fatty acids: short-chain (4 to 10 carbons), medium-chain (11 to 16 carbons), long-chain (17 to 22 carbons), saturated, and unsaturated fatty acids. The data set included 49,127 test-day records from 10,029 first-lactation Holstein cows in 810 herds. The random regression animal test-day model included days in milk, herd-test date, and age-season of calving (polynomial regression) as fixed effects, herd-year of calving, animal additive genetic effect, and permanent environment effects as random polynomial regressions, and random residual effect. Legendre polynomials of the third degree were selected for the fixed regression for age-season of calving effect and Legendre polynomials of the fourth degree were selected for the random regression for animal additive genetic, permanent environment, and herd-year effect. The average daily heritability over the lactation for the medium-chain fatty acid group (0.32) was higher than for the shortchain (0.24) and long-chain (0.23) fatty acid groups. The average daily heritability for the saturated fatty acid group (0.33) was greater than for the unsaturated fatty acid group (0.21). Estimated average daily genetic correlations were positive among all fatty acid groups and ranged from moderate to high $(0.63-0.96)$. The genetic correlations illustrated similarities and differences in their origin and the makeup of the groupings based on chain length and saturation. These results provide evidence for the existence of genetic variation in midinfrared predicted fatty acid groups, and the possibility of improving milk fatty acid profile through genetic selection in Canadian dairy cattle.

Key words: milk fatty acid, mid-infrared, random regression model, heritability

Received November 1, 2016

Accepted January 25, 2017.

${ }^{1}$ Corresponding author: fleminga@uoguelph.ca

\section{INTRODUCTION}

Milk contains essential nutrients needed for young mammals as well as for humans. The main components of milk are water, lipids, proteins, carbohydrates, salts, and vitamins (Månsson, 2008). Milk fat contains approximately 400 different fatty acids (Jensen et al., 1991). Almost $70 \%$ of the fatty acids in milk are saturated, $25 \%$ are monounsaturated, $2.3 \%$ are polyunsaturated, and $2.7 \%$ are trans fatty acids (Månsson, 2008). Milk fat composition reflects the metabolism and environment of the cow, and affects the nutritional, technological and sensory quality, and economic value of milk and milk products (Bastin et al., 2011). In nutritional terms, whereas some fatty acids are beneficial to human health (CLA and omega fatty acids), some may have negative effects. Human intervention studies have shown that lauric (C12:0), myristic (C14:0), and palmitic acid (C16:0) significantly elevate the low-density lipoprotein cholesterol, whereas stearic acid (C18:0) had no effect on serum lipid (Denke and Grundy, 1992; Zock et al., 1994; Temme et al., 1996; Mensink et al., 2003). Despite well-established evidence, the association of SFA with human health is still controversial. Increasing concern about health and diet has created a need for researchers to investigate ways to alter milk fat composition. In addition to food processing, milk fat composition can be modified mainly through feeding and genetics (Palmquist et al., 1993; DePeters et al., 1995). Many studies have reported changes in milk fat composition by feeding different diets and supplementations (Grummer, 1991; Chilliard et al., 2001). However, only a small number of studies have estimated the genetic variability in the fatty acid profile of milk measured using GC (Renner and Kosmack, 1974; Karijord et al., 1982; Bobe et al., 2008; Stoop et al., 2008; Garnsworthy et al., 2010). The number of samples was generally limited when GC was used for the quantification of fat composition.

Soyeurt et al. (2006a) first developed calibration equations for fatty acids using mid-infrared (MIR) spectrometry. Results indicated that the developed cali- 
Table 1. Definition of milk fatty acid groups

\begin{tabular}{ll}
\hline Fatty acid group & Individual fatty acids included \\
\hline Short-chain & C4:0, C6:0, C8:0, C10:0 \\
Medium-chain & C11:0, C12:0, C13:0, C14:0, C14:1, C15:0, C16:0, C16:1 \\
Long-chain & C17:0, C18:0, C17:1, C18:1n-9 trans, C18:1n-9 cis, C18:02n-6 trans, C18:02n-6 cis, C18:3n-3, C22:6n-3, CLA \\
Saturated & C4:0, C6:0, C8:0, C10:0, C11:0, C12:0, C13:0, C14:0, C15:0, C16:0, C17:0, C18:0 \\
Unsaturated & C14:1, C16:1, C17:1, C18:1n-9 trans, C18:1n-9 cis, C18:02n-6 trans, C18:02n-6 cis, C18:3n-3, C22:6n-3, CLA \\
\hline
\end{tabular}

bration equations for C10:0, C12:0, C14:0, C16:0, C16:1 cis-9, C18:1, and saturated and monounsaturated fatty acids in milk could be used with high accuracy. The use of MIR spectroscopy for predicted milk fatty acid contents is less expensive and requires less labor than GC. Therefore, MIR prediction of fatty acid contents can generate larger data sets, potentially resulting in increases in the accuracy of genetic parameters estimates (Soyeurt et al., 2006a). Following these results, several studies have investigated the genetic variability of MIR-predicted individual fatty acids, as well as groups of fatty acids (Soyeurt et al., 2007a,b, 2008a,b; Gion et al., 2011; Bastin et al., 2011; Lopez-Villalobos et al., 2014). Generally, these studies revealed that de novo synthesized fatty acids are under more genetic control than preformed fatty acids (fatty acids synthesized from dietary lipids and body fat reserves). Additionally, SFA are more heritable than UFA. Soyeurt et al. (2007b) reported high genetic correlations among fatty acids of similar origin, and therefore, suggested developing a selection index by incorporating groups of fatty acids of similar origin rather than distinct individual fatty acids.

Milk MIR spectroscopy is the standard method for Canadian DHI laboratories to quantify fat and protein contents for payment and animal performance recording purposes. To take further advantage of these already existing practice and acquired spectral data, Fleming (2016) developed calibration equations to predict fatty acid composition from the MIR spectra of milk for the Canadian dairy industry. No previous estimation has been done of genetic parameters for MIR-predicted fatty acids in the Canadian dairy population. Investigating fatty acid profile in depth using the large number of MIR-predicted fatty acid phenotypes would provide useful information to perform selection and genetic improvement of the milk fatty acid profile efficiently. Moreover, phenotypic information on the fatty acid profile could potentially be used for herd management, including feeding, health, and reproduction.

The objectives of this study were to investigate the phenotypic and genetic variation of 5 groups of MIR predicted fatty acids: short-chain, medium-chain, longchain, saturated, and unsaturated fatty acids.

\section{MATERIALS AND METHODS}

\section{Data}

Milk MIR spectra obtained during routine milk recording from either CanWest DHI (Guelph, ON, Canada) or Valacta (Sainte-Anne-de-Bellevue, QC, Canada) laboratories were collected and stored in a database. The individual milk spectra from the 2 laboratories were obtained from MilkoScan FT6000 spectrometers (FOSS, Hillerød, Denmark) with identical specifications and procedures used. Milk spectral records were standardized across the 2 instruments and across time as described by Bonfatti et al. (2017). Fatty acid data used in this study were predicted by applying the calibration equations developed by Fleming (2016). Fatty acids were classified into 5 groups based on the length of the carbon chain and by saturation: short-chain (4 to 10 carbons), medium-chain (11 to 16 carbons), longchain (17 to 22 carbons), saturated (no double bond), and unsaturated (one or more double bonds). Definitions of the milk fatty acid groups are given in Table 1.

The coefficient of determination of the cross-validation $\left(\mathbf{R}_{\text {cv }}^{2}\right)$ and ratio of performance deviation of the used calibration equations (Fleming, 2016) are shown in Table 2. Not all fatty acids were predicted with the same accuracy from the MIR spectra. The $\mathrm{R}_{\mathrm{cv}}^{2}$ for the short-chain fatty acid group was $70.69 \%$, which was lower than that for the other fatty acid groups. The lower predictability for the short-chain fatty acid group may have an effect on the estimation of genetic parameters. The predicted fatty acid values were expressed in grams per deciliter of milk and log-transformed to improve normality.

\section{Data Editing}

The initial data set of predicted fatty acids had 2,053,396 test-day records from 569,260 Holstein cows in 6,785 herds, collected from January 2013 to July 2015. Only test-day records between 5 and 305 DIM were considered for the genetic analysis $(1,499,607$ records from 488,047 cows in 6,759 herds). Only a small proportion of the FOSS lines present in Canadian DHI laboratories (2 out of 12 ) currently output milk spectral 
records, and as a result not all test-day milk samples from a given cow have spectral data saved. Which samples are selected to go through these lines was largely random. For this reason, only herds with more than 70 cows were chosen to have enough repeated test-day fatty acid records per cow to effectively model the shape of a lactation curve using a random regression model (1,100,810 records from 338,431 cows in 2,858 herds). Further, only first-lactation Holstein cows with an age at calving between 19 and 43 mo were considered for the analysis (390,068 records from 174,545 cows in 2,858 herds). Cows were required to have their first test-day within the first 50 DIM, and records were deleted for a given herd $\times$ test-day if fewer than 4 records were available. Moreover, cows were expected to have fatty acid records for at least 4 test-days. The last 3 criteria were applied in a loop sequence until a constant number of test-day fatty acid records were achieved. The final data set included 49,127 records from 10,029 Holstein cows in 810 herds. Descriptive statistics of the data set after editing are shown in Table 2. An animal pedigree file generated by tracing back the pedigrees of sires and dams as far back as possible was provided by the Canadian Dairy Network (Guelph, ON) and contained a total of 76,074 animals.

\section{Models}

The following general random regression animal testday model was used for all the analyses:

$$
\mathbf{y}=\mathbf{X} \boldsymbol{\beta}+\mathbf{Z}_{\mathrm{hy}} \mathbf{h y}+\mathbf{Z}_{\mathrm{a}} \mathbf{a}+\mathbf{Z}_{\mathrm{p}} \mathbf{p}+\mathbf{e}
$$

where $\mathbf{y}$ is a vector of observations [fatty acid content $\ln (\mathrm{g} / \mathrm{dL}$ of milk $)] ; \boldsymbol{\beta}$ is a vector of systematic effects of herd-test date, DIM (defined as single day classes), and fixed Legendre polynomial coefficients for age-season of calving (4 seasons: January-March, April-June, JulySeptember, and October-December); hy is a vector of random Legendre polynomial coefficients for herd-year of calving effect; $\mathbf{a}$ is a vector of random Legendre polynomial coefficients for animal additive genetic effect; $\mathbf{p}$ is a vector of random Legendre polynomial coefficients for permanent environmental effect; $\mathbf{X}, \mathbf{Z}_{\mathrm{hy}}, \mathbf{Z}_{\mathrm{a}}$, and $\mathbf{Z}_{\mathrm{p}}$ are the corresponding incidence matrices for the fixed, herd-year of calving, animal additive genetic, and permanent environment effects, respectively; and $\mathbf{e}$ is a vector of random residuals.

The expectations and (co)variance structure for the random effects, all assumed normally distributed, were

$$
\mathbf{E}\left[\begin{array}{c}
\mathbf{y} \\
\mathbf{h y} \\
\mathbf{p} \\
\mathbf{a} \\
\mathbf{e}
\end{array}\right]=\left[\begin{array}{c}
\mathbf{X} \boldsymbol{\beta} \\
0 \\
0 \\
0 \\
0
\end{array}\right]
$$

and

$$
\mathbf{V}\left[\begin{array}{c}
\mathbf{h y} \\
\mathbf{p} \\
\mathbf{a} \\
\mathbf{e}
\end{array}\right]=\left[\begin{array}{cccc}
\mathbf{H} & 0 & 0 & 0 \\
0 & \mathbf{P} & 0 & 0 \\
0 & 0 & \mathbf{G} & 0 \\
0 & 0 & 0 & \mathbf{E}
\end{array}\right]
$$

where $\mathbf{H}=\mathbf{I} \otimes \mathbf{H}_{0} ; \mathbf{P}=\mathbf{I} \otimes \mathbf{P}_{0} ; \mathbf{G}=\mathbf{A} \otimes \mathbf{G}_{0}$; and $\mathbf{I}$ is an identity matrix; $\mathbf{A}$ is the additive relationship matrix; $\mathbf{H}_{0}, \mathbf{P}_{0}$, and $\mathbf{G}_{0}$ are (co)variance matrices for herdyear of calving, permanent environment, and additive genetic regression coefficients, respectively; $\mathbf{E}$ is a block-diagonal residual (co)variance matrix, assumed heterogeneous across 20 classes of 15 DIM; and $\otimes$ is the Kronecker product.

\section{Selection of Suitable Legendre Polynomial and Model Comparisons}

Single-trait models were used to determine the significance of fixed effects and the best degree of the fixed Legendre polynomial regression for age-season of calving effect using ASReml (Gilmour et al., 2009). Bayesian methods via Gibbs sampling were then used to find the best degree of the Legendre polynomial for the random regressions using single-trait models. Deviance information criterion (DIC) values for models

Table 2. The coefficient of determination of the cross-validation $\left(\mathrm{R}_{\mathrm{cv}}^{2}\right)$, ratio of performance deviation (RPD), and descriptive statistics of analyzed data $(\mathrm{n}=49,127)$ for the 5 groups of fatty acids

\begin{tabular}{lcccccc}
\hline Fatty acid group & $\mathrm{R}_{\text {cv }}^{2}(\%)$ & $\mathrm{RPD}^{1}$ & Mean & $\mathrm{SD}$ & Minimum & Maximum \\
\hline Short-chain & 70.69 & 1.85 & 0.356 & 0.057 & 0.054 & 0.635 \\
Medium-chain & 89.17 & 3.04 & 1.136 & 0.127 & 0.505 & 1.800 \\
Long-chain & 80.17 & 2.25 & 0.882 & 0.124 & 0.397 & 1.828 \\
Saturated & 93.37 & 3.88 & 1.349 & 0.125 & 0.644 & 1.989 \\
Unsaturated & 82.11 & 2.36 & 0.754 & 0.108 & 0.319 & 1.629 \\
\hline
\end{tabular}

${ }^{1}$ From Fleming (2016). 
Table 3. Deviance information criterion values for models with different degree of Legendre polynomial for the 5 groups of fatty acids

\begin{tabular}{lccccc}
\hline Degree & Short-chain & Medium-chain & Long-chain & Saturated & Unsaturated \\
\hline 0 & $-183,684$ & $-117,679$ & $-116,279$ & $-112,570$ & $-128,700$ \\
1 & $-188,726$ & $-122,920$ & $-119,040$ & $-117,232$ & $-131,850$ \\
2 & $-192,046$ & $-126,512$ & $-121,401$ & $-120,678$ & $-134,615$ \\
3 & $-195,563$ & $-130,590$ & $-124,171$ & $-124,418$ & $-137,591$ \\
4 & $-199,075$ & $-134,939$ & $-127,481$ & $-128,708$ & $-141,296$ \\
\hline
\end{tabular}

with different degree of random regressions were estimated by keeping the best degree for fixed regression for age-season of calving constant. In addition, the same increasing degree for all 3 random regressions was assumed (Table 3). Five single-trait models were fitted using Bayesian methods via Gibbs sampling to estimate posterior means of covariance components, assuming heterogeneous residual variance in 20 DIM classes of equally spaced intervals of 15 . The 5 single-trait models were as follows: $\mathrm{M}_{0}=$ model with Legendre polynomial of degree 0 (intercept), $\mathrm{M}_{1}=$ model with Legendre polynomial of degree 1 ( 2 coefficients), $\mathrm{M}_{2}=$ model with Legendre polynomial of degree 2 (3 coefficients), $\mathrm{M}_{3}=$ model with Legendre polynomial of degree 3 (4 coefficients), and $\mathrm{M}_{4}=$ model with Legendre polynomial of degree 4 ( 5 coefficients). Regression curves were modeled using Legendre polynomial as in Jamrozik et al. (2002) and were as follows: $\mathrm{L} 0=1.0, \mathrm{~L} 1=3^{0.5} \mathrm{x}, \mathrm{L} 2$ $=5^{0.5}\left(1.5 \mathrm{x}^{2}-0.5\right), \mathrm{L} 3=7^{0.5}\left(2.5 \mathrm{x}^{3}-1.5 \mathrm{x}\right)$, and $\mathrm{L} 4=$ $9^{0.5}\left(35 \mathrm{x}^{4}-30 \mathrm{x}^{2}+3\right) / 8$, where $\mathrm{x}=2(\mathrm{t}-5) / 300-1$, and $\mathrm{x}$ is a standardized (in interval from -1 to +1 ) time.

The best single-trait model for the 3 random effects was selected based on the DIC value. The smaller the DIC value, the better the model fit (Spiegelhalter et al., 2002). Posterior means and standard deviations of (co)variance components were estimated using 70,000 samples after 30,000 burn-in iterations. Prior values were set to 0.01 for variances and 0 for co-variances.

\section{Estimation of Genetic Parameters Using Multiple Trait Model}

A 5-trait random regression animal test-day model was used to estimate the genetic parameters. The best degree of Legendre polynomial from the above univariate analysis for both fixed and random regressions were used for the multi-trait analysis. The Bayesian methods via Gibbs sampling were based on posterior means of parameters estimated using 270,000 samples after a burn-in of 30,000 samples assuming heterogeneous residual variance in 15 DIM intervals. Prior values were set to 0.01 for variances and 0 for co-variances. Flat prior distributions were assumed for all fixed effects.
All random effects were assumed to have a nonzero covariance between traits.

Daily heritability was calculated for 5 to $305 \mathrm{~d}$ and was defined as the additive genetic variance divided by the sum of the herd-year of calving, additive genetic, permanent environmental, and residual variances. Average daily heritability was estimated by the sum of all the daily heritabilities divided by 300 . Additive genetic correlations $\left(\mathrm{r}_{\mathrm{g}}\right)$ were calculated as

$$
\mathrm{r}_{\mathrm{g}}=\frac{\operatorname{Cov}\left(t_{1}, t_{2}\right)}{\sqrt{v 1 \times v 2}},
$$

where Cov is the additive genetic covariance between trait $1\left(t_{1}\right)$ and trait $2\left(t_{2}\right)$, and $v 1$ and $v 2$ are the additive genetic variance for trait 1 and trait 2 , respectively. Average correlation between traits was estimated by the sum of daily genetic correlation (5-305 DIM) divided by 300 . Average daily herd-year of calving, permanent environment, residual, and phenotypic correlations were estimated using their corresponding variances and covariances.

\section{RESULTS AND DISCUSSION}

\section{Descriptive Statistics}

On average, the proportions of short-chain, mediumchain, and long-chain fatty acid groups were 15, 47.85, and $37.15 \%$, respectively. These fatty acid percentages were comparable to those found by Bastin et al. (2011) who examined the same groupings $(8.42,51.47$, and $40.12 \%$ for short-chain, medium-chain, and long-chain fatty acids, respectively). The percentages of the various fatty acid groups might differ in other studies as a result of how the fatty acids groups were defined. The medium-chain fatty acid group represented the bulk of the milk fatty acids in the current study because included in this group are 2 major milk fatty acids: C14:0 and C16:0. Månsson (2008) reported C14:0 and C16:0 account for approximately 11 and $30 \%$ of total weight of fatty acids, respectively. Similarly, Stoop et al. (2008) observed a high percentage for the 14- to 16-carbon group of fatty acids (44.24\% of total fat). 
In the current study, saturated and unsaturated fatty acid groups represented 64.15 and $35.85 \%$ of the total fatty acids, respectively. Due to the biohydrogenation of dietary unsaturated fatty acids that takes place in the rumen, the amount of UFA absorbed is minimal. Thus, their incorporation into milk is lower than that for SFA (Sauer et al., 1998). This is in agreement with other studies (Grummer, 1991; Jensen, 2002; Månsson, 2008).

Figure 1 shows the phenotypic variation of fatty acid groups across the lactation. Higher amounts of SFA were observed across the entire lactation compared with UFA in the present study. This is in accordance with the overall lactation estimates reported by Grummer (1991). Long-chain fatty acid contents followed the same trend as UFA, as most of the long-chain fatty acids are UFA. Likewise, short-chain and medium-chain fatty acids followed a similar trend as SFA. This is because most of the fatty acids in the short-chain as well as medium-chain fatty acid groups are SFA (Table 1). Short-chain and medium-chain show similar trends because both groups of fatty acids are produced from de novo synthesis, whereas long-chain fatty acids are derived from blood lipids. However, C16:0 is produced from both de novo synthesis and blood lipids (Bauman and Griinari, 2003).

The effect of stage of lactation in milk fatty acid composition has been reported by many studies (Karijord et al., 1982; Kay et al., 2005; Garnsworthy et al., 2006; Soyeurt et al., 2008a; Mele et al., 2009; Bastin et al., 2011). In the current study, contents of fatty acid groups were more variable during the initial part of lactation compared with mid and late lactation (Figure 1). In early lactation, long-chain fatty acid contents decreased more rapidly than short-chain and mediumchain fatty acids. In the same way, UFA decreased more in early lactation than SFA. This result is in accordance with Bastin et al. (2011), who also found high variation for the MUFA group as well as monounsaturated individual fatty acids (e.g., C18:1, C18:1 cis, and C18:1 cis9) compared with SFA for 4 DIM classes (1-20, 21-40, $41-60$, and $61-80$ DIM) as a proportion of their concentration at class 81 to 100 DIM. They also observed greater variation in long-chain than medium-chain and short-chain fatty acid groups in early lactation. Soyeurt et al. (2008a) also observed a similar pattern of saturated and monounsaturated fatty acid content over the lactation. The distribution of fatty acid contents over the lactation could be explained by the energy status of cow.

An increased content of long-chain and unsaturated fatty acids observed at the very beginning of the lactation is likely due to the negative energy balance status of the cow. As mentioned by Garnsworthy et al. (2006), the fatty acid profile of milk is the output of complex interactions between feed intake, diet composition, body fat mobilization, liver metabolism, rumen fermentation, mammary absorption, and synthesis of fatty acids. Thus, when cows are in negative energy balance during early lactation, energy requirements are high and feed intake is low, which leads to the increased mobilization of body fat (Garnsworthy and Topps, 1982; Palmquist

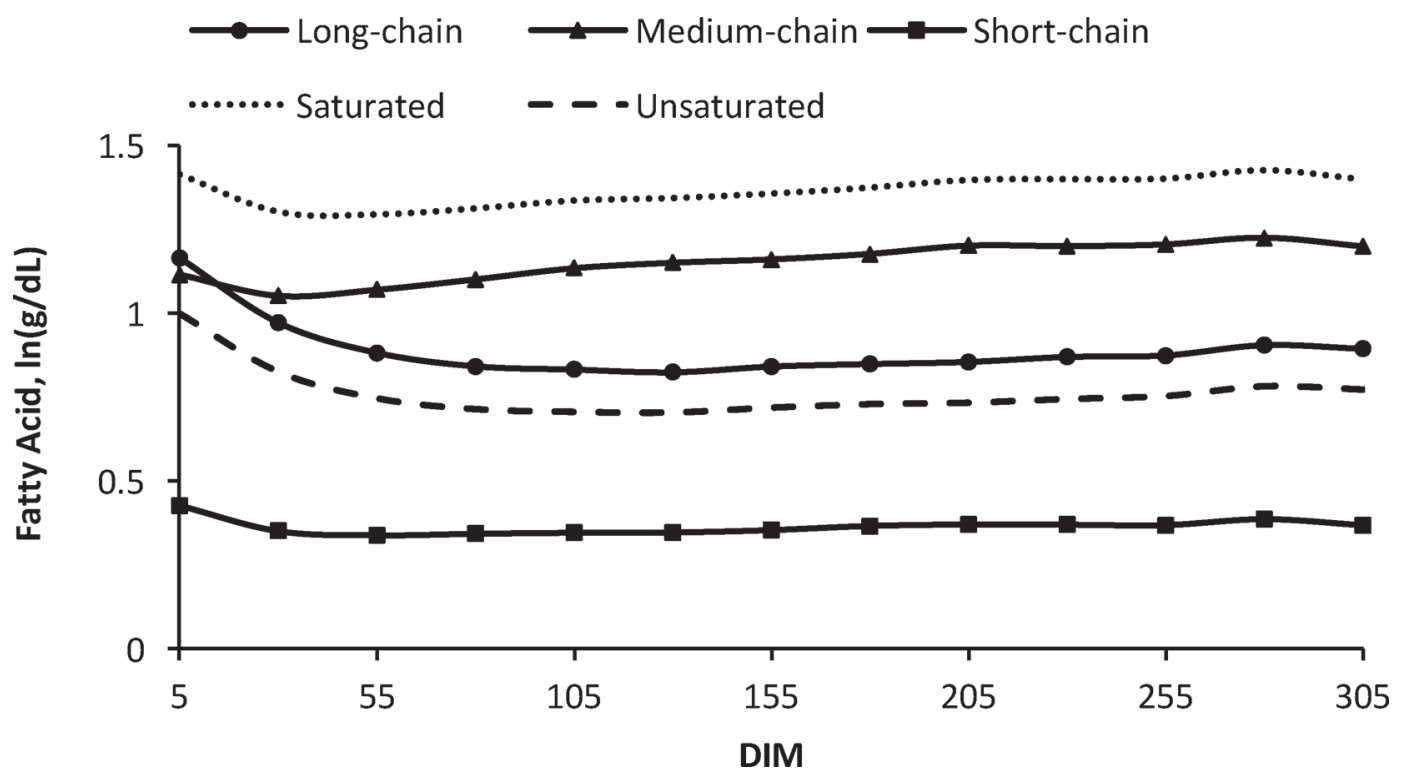

Figure 1. Quantity of short-chain, medium-chain, long-chain, saturated, and unsaturated fatty acid groups across lactation of first-lactation Holstein cows. 
et al., 1993). In adipose tissues, the main fatty acids forming the stored triacylglycerides are C16:0, C18:0, and C18:1 cis-9. The mobilization of body fat causes direct incorporation of these fatty acids into the milk in early lactation (Christie, 1981; Chilliard et al., 2000). However, studies have reported higher contents of $\mathrm{C} 18$ family fatty acids than C16:0 in milk during high lipolysis in early lactation (Barber et al., 1997; Bastin et al., 2011). Bauman and Griinari (2003) reported that when cows are in negative energy balance, fatty acids produced from body fat reserve mobilization increases in direct proportion to the energy state. As the lactation progresses, cows start to stabilize their energy balance and body fat mobilization decreases. Therefore, incorporation of these fatty acids into milk lowers and becomes constant. This results in a decrease in long-chain fatty acid contents after the initial stage of lactation. Lower quantities of de novo synthesized fatty acids (short-chain and medium-chain fatty acids) in the initial stage of lactation may be in part caused by the high content of long-chain fatty acid. Long-chain fatty acids inhibit the mammary lipogenic enzyme, acetylcoenzyme A carboxylase, which catalyzes the synthesis of malonyl-CoA, a catabolic intermediate in fatty acid synthesis (Palmquist et al., 1993; Bastin et al., 2011). In mid and late lactation, fatty acid group contents become more constant as the cows attain a positive energy balance and the inhibitory effect of long-chain fatty acids on de novo synthesized fatty acids is reversed back. Similarly, Garnsworthy et al. (2006) and Kgwatalala et al. (2009) found no differences in the fatty acid profile in mid and late lactation. Therefore, the phenotypic variation found in the present fatty acid group contents may be useful in the evaluation of cow energy status in early lactation.

\section{Suitable Legendre Polynomials}

Wald $F$-statistics showed third-degree Legendre polynomial (cubic) was significant for the fixed ageseason of calving effect. The most suitable Legendre polynomial for the random effects was chosen based on the DIC values of the 5 alternate models that had the same degree of Legendre polynomial for age-season of calving (third degree) and included different degrees of Legendre polynomial [from 0 (intercept only) to 4 (quartic)] for the random effects. The DIC values decreased with the increase in the degree of Legendre polynomials (Table 3). Fourth-degree random regressions yielded the best fit based on the lowest DIC value (Table 3). No polynomials with a degree higher than 4 were fitted due to the low number of cows with more than 5 fatty acid measurements and the cubic shape of the phenotypic distribution of the fatty acid groups.

\section{Heritability}

Average daily heritabilities for fatty acids from the multiple-trait analysis are shown in Table 4. Posterior standard deviations for the estimated average daily heritabilities ranged from 0.00065 to 0.00193 . Average daily heritabilities were 0.24 for short-chain, 0.32 for medium-chain, 0.23 for long-chain, 0.33 for saturated, and 0.21 for UFA. These estimates were lower than the heritability estimates reported by Bastin et al. (2011) for short-chain, medium-chain, and saturated (0.44, 0.43 , and 0.43 , respectively), but similar for long-chain (0.20) and unsaturated (0.22) fatty acids in milk (g/ $\mathrm{dL}$ ). The greatest difference was for short-chain fatty acids, where the estimate from Bastin et al. (2011) was much higher than the heritability estimated in the current study. The lower heritability estimated in the present study might be due to the lower accuracy of the short-chain fatty acid calibration equation used $\left(\mathrm{R}_{\mathrm{cv}}^{2}=\right.$ $70.69 \%$ ). Previous studies have reported that heritability tends to decrease with an increase in carbon chain length of milk fatty acids (Renner and Kosmack, 1974; Bastin et al., 2011). However, in the present study, the heritability estimated for the short-chain fatty acid group was low. In general, fatty acids produced from de novo synthesis (i.e., short-chain and medium-chain) are under more genetic control than preformed (i.e., long-chain) fatty acids (Renner and Kosmack, 1974; Karijord et al., 1982; Bastin et al., 2011). This was observed in the present study, where medium-chain fatty acids had a higher average daily heritability than long-chain fatty acids. However, the heritabilities estimated for short-chain and long-chain fatty acids were similar. De novo synthesis involves metabolic enzymes, such as acetyl-coenzyme A carboxylase and fatty acid synthetase (Chilliard et al., 2000; Bauman and Griinari, 2003), which are under genetic control. On the contrary, preformed fatty acids are taken up by the mammary gland from circulating blood lipids. The circulating lipids in the blood are produced from lipoproteins and nonesterified fatty acids derived from the digestive tract during the absorption of lipids, and from the mobilization of body fat reserves (Bauman and Davis, 1973; Barber et al., 1997). This may be one of the reasons for the lower heritability estimated for the long-chain fatty acid group. The heritability of 0.23 for long-chain fatty acids, however, indicates that the process of their incorporation into milk is partially under genetic control.

A higher heritability was found for the SFA group than for the UFA group. This is due to the fact that most of the de novo synthesized fatty acids are saturated because of the low activity of the $\Delta^{9}$ desaturase enzyme on fatty acids shorter than 18 carbons in length 
(Chilliard et al., 2000). However, a small proportion of C14:0 and C16:0 are desaturated to C14:1 and C16:1 (Chilliard et al., 2000). As well, most UFA are preformed fatty acids derived from blood lipids. Bastin et al. (2013) also reported greater heritabilities for saturated compared with unsaturated MIR-predicted fatty acids (g/dL of milk) for each of first-, second-, and third-parity Holsteins. Similarly, in Italian Holsteins, Penasa et al. (2015) found a greater heritability of 0.246 for saturated compared with 0.069 for unsaturated MIR-predicted fatty acids (g/100 g of milk), although both estimates are lower in magnitude.

Daily heritabilities for short-chain, medium-chain, and long-chain, and saturated and unsaturated fatty acid groups are shown in Figure 2. Posterior standard deviations for the daily heritabilities ranged from 0.000076 to 0.000628 . Heritabilities for all fatty acid groups were lower in the beginning of lactation until approximately 45 DIM. In mid lactation, heritabilities tended to increase, followed by a decrease for shortchain, medium-chain, and saturated fatty acids, whereas the long-chain and unsaturated fatty acid groups slightly increased. Lower heritabilities in early lactation may be due to high residual variance estimates found in the beginning of lactation compared with mid and late lactation in this study (Figure 3). The variances across lactation for genetic, herd-year of calving, and permanent environmental effects estimated in the current study are shown in Appendix Figures A1, A2, and A3. Variation of heritabilities in early lactation may be due to negative energy balance, lipolysis of adipose tissue, and inhibition of de novo synthesis by longchain fatty acids (Soyeurt et al., 2008a). As the cows reached positive energy balance, heritability increased. Variation of heritability among fatty acid groups in late lactation may be due to the low number of test-day records in late lactation. A similar pattern was observed by Soyeurt et al. (2008a) for the MUFA group in milk (g/100 g of milk). Although high heritabilities during mid lactation were reported by Bastin et al. (2011), the variation of daily heritabilities in early lactation was not clearly visible.

\section{Correlations}

Average daily genetic correlations among fatty acids were estimated from the multivariate analysis (Table 4). All genetic correlations were positive among fatty acid groups and ranged from moderate to high (0.63-0.96). Posterior standard deviations for average daily genetic correlations were low (less than 0.001). The estimated genetic correlations between the fatty acid groups illustrate similarities and differences in their origin and the makeup of the groupings based on chain length and saturation. The accuracy of the predictions may also influence the genetic correlations, as a result of the introduction of various degrees of prediction error. A high genetic correlation of 0.86 was found between short-chain and medium-chain fatty acids, which indicates their similar origin. The lower genetic correlation estimated for long-chain fatty acids with short-chain (0.70) and medium-chain fatty acids (0.73) is due to their different origins. As expected, high genetic correlations were found for the SFA group with short-chain and medium-chain fatty acid groups. Saturated fatty acids consist of almost $80 \%$ short-chain and mediumchain fatty acids (Månsson, 2008). A genetic correlation of 0.86 was estimated between long-chain and unsaturated fatty acids, thus supporting that the UFA are mostly also long-chain fatty acids. These estimated values were slightly different from estimates of Bastin et al. (2011) examining first-parity cows and subsequent work by Bastin et al. (2013) across parities, even though similar groupings of fatty acids were used. The estimated genetic correlations in the present study were higher than those reported by Bastin et al. (2011, 2013) except for genetic correlations between short-chain and medium-chain, unsaturated and long-chain, short-chain and saturated, and medium-chain and saturated fatty acid groups. This might be due to differences in the number of samples, model, population, and units (logtransformed) used. Also, Bastin et al. (2011, 2013) approximated daily genetic correlations among traits from correlations among daily breeding values, not using a multivariate model like the present study used.

Table 4. Average daily heritability (on diagonal), ${ }^{1}$ average daily genetic correlation (above diagonal) ${ }^{2}$ and average daily phenotypic correlation (below diagonal) for fatty acid groups in first-lactation Holstein cows

\begin{tabular}{lccccc}
\hline Fatty acid group & $\begin{array}{c}\text { Short- } \\
\text { chain }\end{array}$ & $\begin{array}{c}\text { Medium- } \\
\text { chain }\end{array}$ & $\begin{array}{c}\text { Long- } \\
\text { chain }\end{array}$ & Saturated & Unsaturated \\
\hline Short-chain & 0.24 & 0.86 & 0.70 & 0.89 & 0.63 \\
Medium-chain & 0.58 & 0.32 & 0.73 & 0.96 & 0.68 \\
Long-chain & 0.38 & 0.45 & 0.23 & 0.77 & 0.86 \\
Saturated & 0.62 & 0.80 & 0.52 & 0.33 & 0.70 \\
Unsaturated & 0.32 & 0.42 & 0.64 & 0.45 & 0.21 \\
li Posterior SD ranged from 0.00065 to 0.00193. & & & \\
${ }^{2}$ Posterior SD all less than 0.001.
\end{tabular}




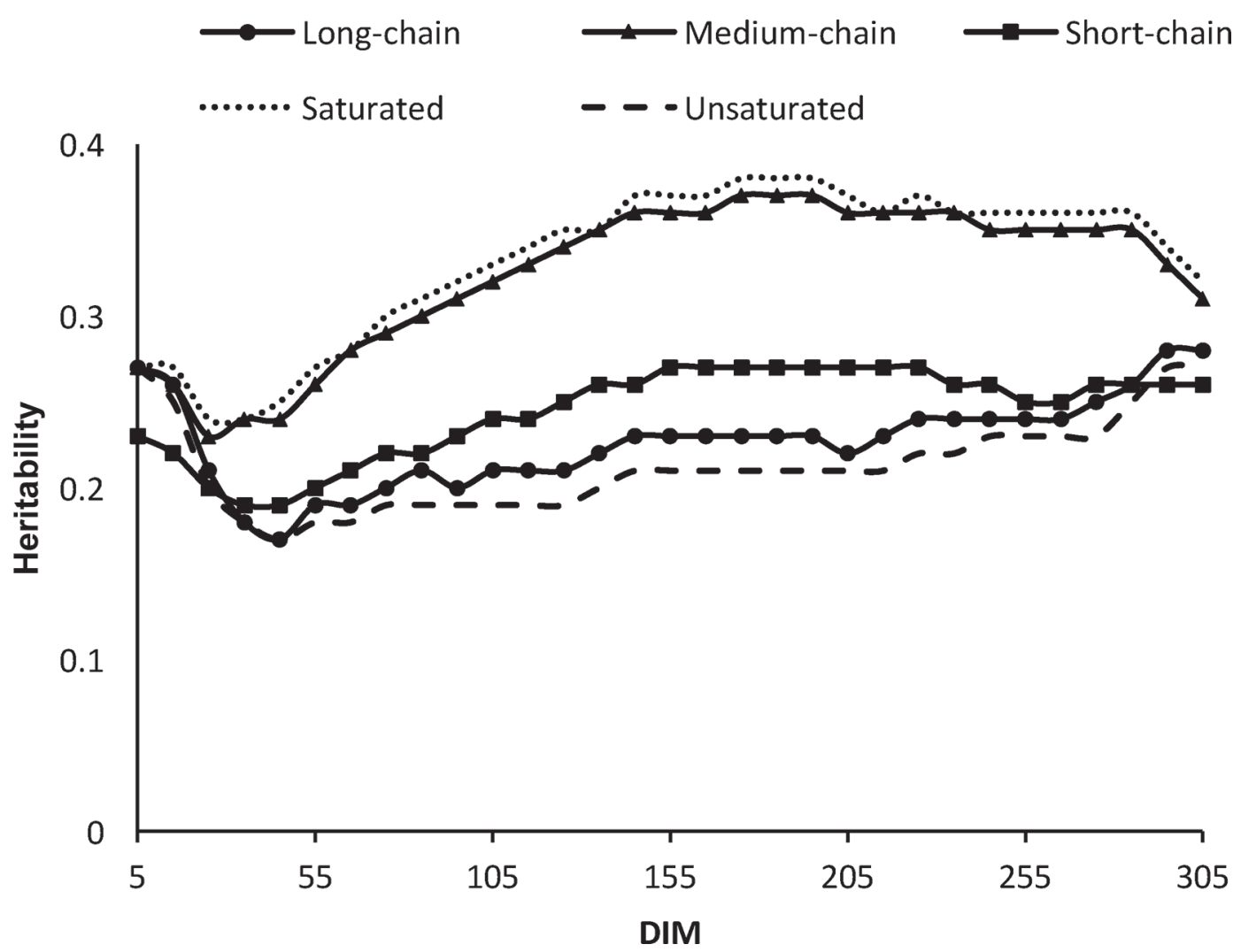

Figure 2. Daily heritabilities of short-chain, medium-chain, long-chain, saturated, and unsaturated fatty acid groups in first-lactation Holstein cows. Posterior SD ranged from 0.000076 to 0.000628.

As presented by Calo et al. (1973), correlations between breeding values do not fully reflect the genetic relationships between traits and might be underestimated. Figure 4 shows genetic correlations among the different fatty acid groups over the lactation. Most of the daily genetic correlations were low in early and late lactation and high in mid-lactation. Genetic correlations found in the present study between saturated and unsaturated fatty acid groups over the lactation (Figure 4d), were similar to those reported between saturated and monounsaturated fatty acids in milk by Soyeurt et al. (2008a). Bastin et al. (2011) described the genetic correlations over the lactation between different individual SFA and C18:1 cis-9, and the genetic correlations were generally low in early lactation and constant during mid and late lactation. Herd-year of calving, permanent environment, and residual correlations for the present study are in Appendix Tables A1 and A2.

Positive and significant average daily phenotypic correlations were observed among 5 fatty acid groups in the current study ranging from 0.32 to 0.80 (Table 4). Similar to the other correlations, phenotypic correlations reflected the similarity in origin of fatty acids.
Soyeurt et al. (2007b) found high phenotypic correlations for the SFA group with C12:0, C14:0, C16:0, and C18:0 expressed as grams per $100 \mathrm{~g}$ of milk. Similarly, high phenotypic correlations were observed between the MUFA group with C18:1 and C18:2. However, Soyeurt et al. (2006b, 2007b) reported different phenotypic correlations between saturated and monounsaturated fatty acid groups ( 0.70 and 0.49 , respectively). This may be due to different number of test-day records, model, and units used in the studies. Bilal et al. (2014) reported a wide range $(-0.01$ to 0.83$)$ of phenotypic correlations for individual fatty acids expressed as a proportion of total fatty acids, which were measured using the GC method. Soyeurt et al. (2008a) observed phenotypic correlations over the lactation between saturated and monounsaturated fatty acid groups in milk and found genetic correlations were lower in initial lactation and increased during mid and late lactation.

\section{Residual Variance}

Residual variances over the lactation are shown in Figure 3. Except for the short-chain fatty acid group, 
higher residual variances were observed for all other fatty acid groups in early lactation. In mid and late lactation, residual variances decreased gradually for medium-chain, long-chain, saturated, and unsaturated fatty acid groups. The residual variance for the shortchain fatty acid group remained constant over mid and late lactation. This may be due the effect of lower predictability of short-chain using MIR spectra. Heterogeneity and lower value of residual variance $(0.00048$ to 0.00556) was observed in Figure 3, thus justifying the choice of separating residual variances in 15 DIM intervals.

\section{Implications}

Mid-infrared spectroscopy offers an opportunity to use a large number of records for genetic analysis, and thus, may provide more accuracy for genetic analyses compared with using the GC method. For efficient genetic improvement, 3 factors are required: genetic variation, selection mechanism, and economic incentive (Gibson, 1991). This study found moderate herita- bilities and moderate to high genetic correlations for groups of milk fatty acids. This provides evidence of genetic variation in these groups and the possibility for modification of fatty acid composition through genetic selection. However, defining the ideal milk fat composition and developing an appropriate selection index with proper weightings for these groups of fatty acids still needs to be completed. The fatty acid proportion that is beneficial in human health may not be favorable for dairy food processing. For example, a higher proportion of UFA and lower amounts of SFA are preferred to reduce cardiovascular diseases (Bauman and Lock, 2010; Micha and Mozaffarian, 2010), but high UFA contents lower the melting point of butter and impair the whipping properties of butter, eventually making it liquid at room temperature. Also, within dairy products, a fatty acid profile good for one product might be detrimental to another. Hence, the ideal fatty acid profile may need to be defined in multiple ways to cater to specific products or niche markets. Defining the milk fatty acid profile to tailor to each specific product may or may not be economical (Gibson, 1991). Thus, defining the

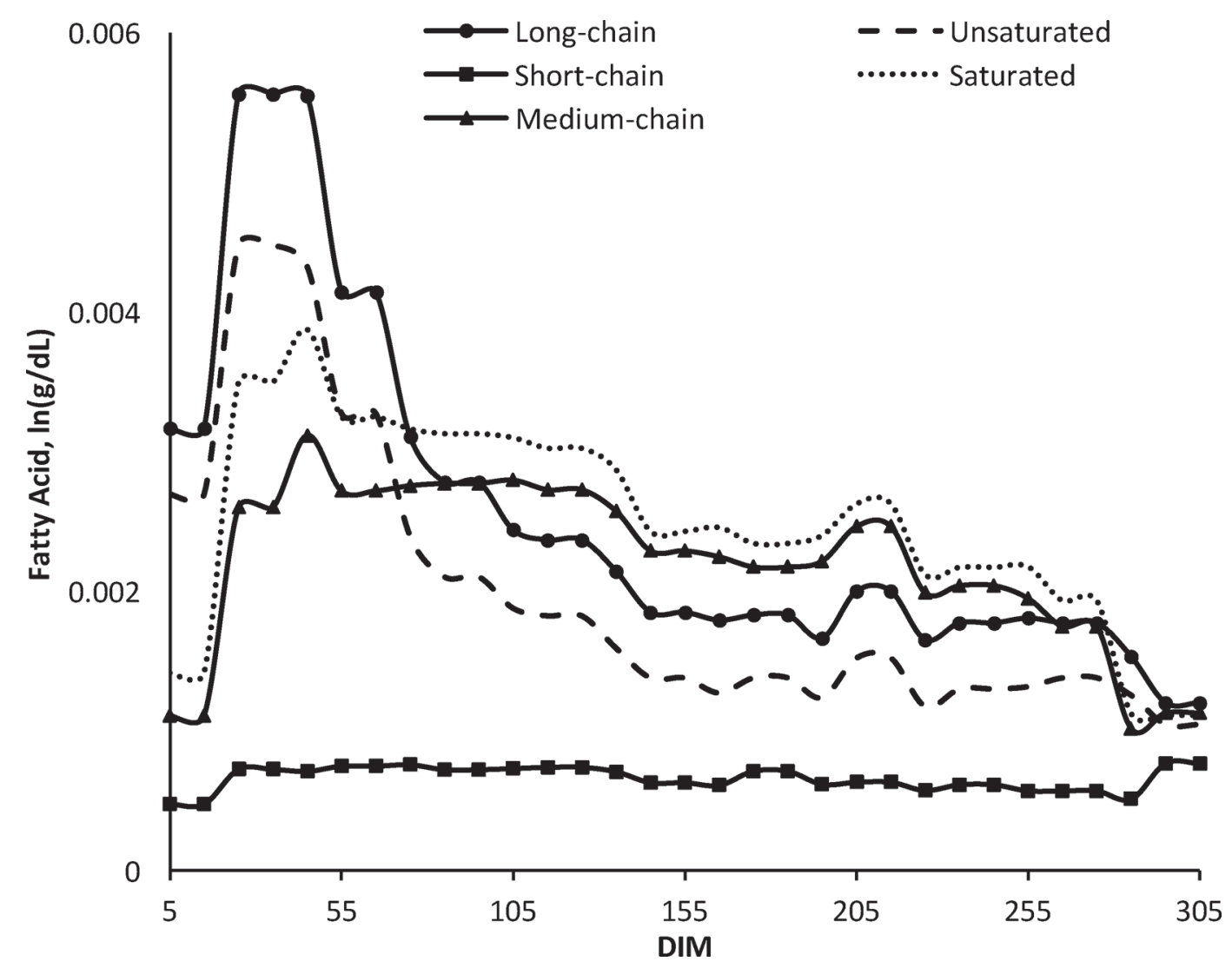

Figure 3. Residual variances over the lactation for long-chain, medium-chain, short-chain, saturated, and unsaturated fatty acid groups in first-lactation Holstein cows. 
(a)

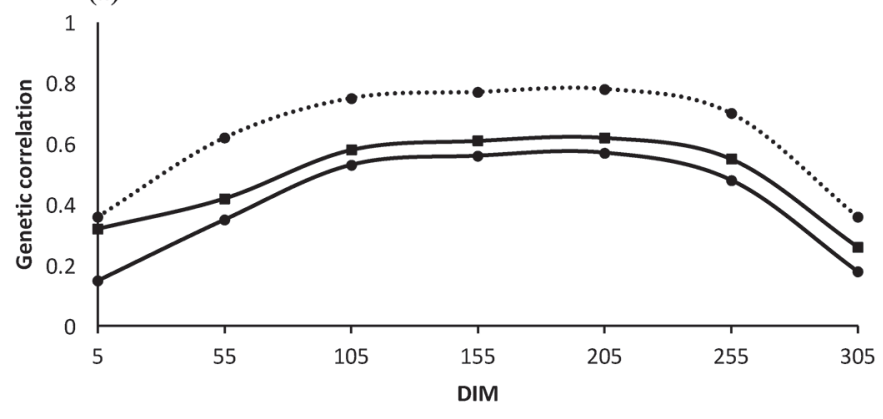

Saturated-Long —-Saturated-Medium $\longrightarrow$ Saturated-Short

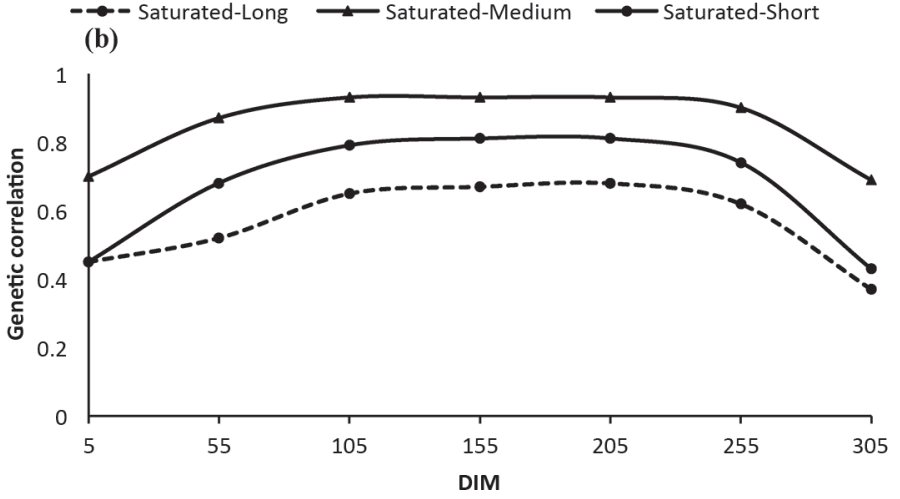

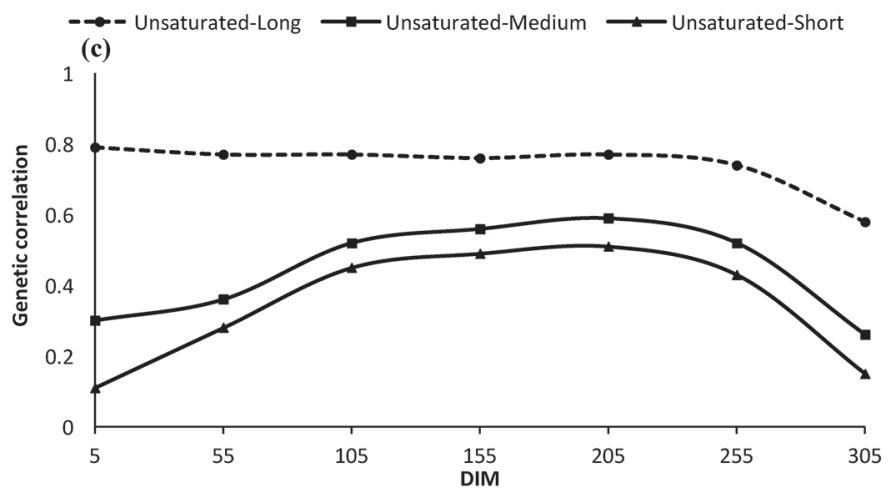

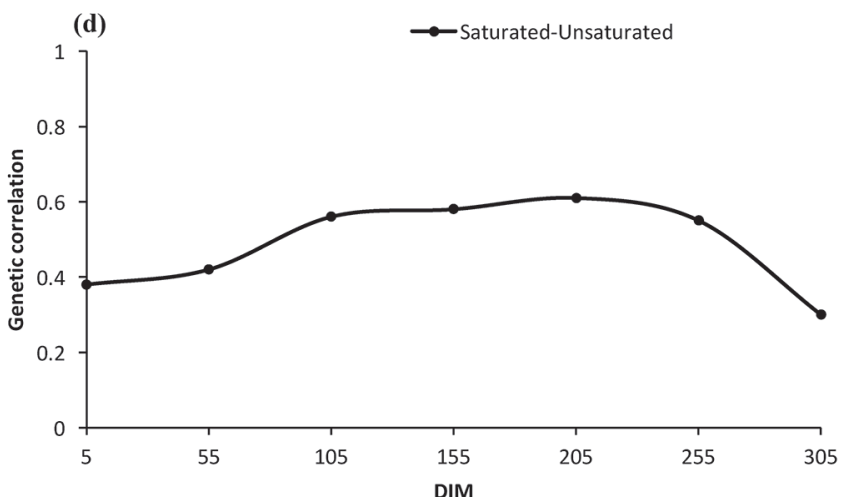

Figure 4. Daily genetic correlations among (a) short-chain, medium-chain, and long-chain fatty acid groups, (b) SFA (saturated) with shortchain, medium-chain, and long-chain fatty acid groups, (c) UFA (unsaturated) with short-chain, medium-chain, and long-chain fatty acid groups, and (d) saturated and unsaturated fatty acid groups in first-lactation Holstein cows.

correct milk fat composition is difficult and more research needs to be done in the future to address these aforementioned issues.

Furthermore, studies have reported negative genetic correlations among proportions of UFA and fat and protein contents (Karijord et al., 1982; Soyeurt et al., 2007b; Stoop et al., 2008). Milk payment is positively associated with fat and protein contents, and therefore, increasing the amount of UFA in milk could affect farmers negatively. This could lead to the development of new payment systems (Arnould and Soyeurt, 2009). Information on milk fatty acids could also be used for other purposes, such as feed and herd management, or as indicators for health and reproductive traits. However, further research would be required.

\section{CONCLUSIONS}

The present work provides evidence for phenotypic and genetic variation in the contents of fatty acids over lactation stages in first-lactation Canadian Holstein cows. The phenotypic variation reflects the association of the milk fatty acid profile with the energy status of the cow, suggesting that the fatty acid profile could be used as an indicator of the energy status of a cow. Moderate heritabilities were estimated for the 5 fatty acid groups. The observed differences in heritabilities showed that de novo synthesized fatty acids are more genetically regulated than the preformed fatty acids. Genetic correlations among all fatty acid groups were positive and ranged from moderate to high. Estimated genetic correlations coincided with the biological pathways of fatty acid synthesis. Therefore, developing a selection index by incorporating groups of fatty acids from similar origins may be beneficial. This research provides evidence for the existence of genetic variation of milk fatty acid groups; thus, changing milk fatty acid composition through genetics may be possible. Moreover, the work done presently is an initial step toward the potential future implementation of genetic evaluation for milk fatty acid contents in the Canadian dairy industry. However, additional research is required to establish how changing milk fatty acid composition could affect the cow (production, reproductive, and health traits), the processing milk industry, and milk for human consumption, and to define proper selection goals for milk fat composition. 


\section{ACKNOWLEDGMENTS}

All dairy producers participating in this project are gratefully acknowledged. We warmly acknowledge Ian Rumbles (now at DRPC, Raleigh, NC) and all the CanWest DHI team (Guelph, ON, Canada) and Daniel Lefebvre and the full team at Valacta (Ste-Anne-deBellevue, QC, Canada) for kindly organizing the selection of herds and collecting samples for the project. This study was partly funded by the DairyGen council of Canadian Dairy Network (Guelph, Ontario, Canada) and the Natural Sciences and Engineering Research Council of Canada (Ottawa, Ontario, Canada). This project is also supported by a contribution from the Dairy Research Cluster Initiative (Dairy Farmers of Canada, Agriculture and Agri-Food Canada, the Canadian Dairy Network, and the Canadian Dairy Commission). We warmly acknowledge FOSS (Hillerød, Denmark) for partial funding and technical support.

\section{REFERENCES}

Arnould, V. M., and H. Soyeurt. 2009. Genetic variability of milk fatty acids. J. Appl. Genet. 50:29-39.

Barber, M. C., R. A. Clegg, M. T. Travers, and R. G. Vernon. 1997. Lipid metabolism in the lactating mammary gland. Biochim. Biophys. Acta 1347:101-126.

Bastin, C., N. Gengler, and H. Soyeurt. 2011. Phenotypic and genetic variability of production traits and milk fatty acid contents across days in milk for Walloon Holstein first-parity cows. J. Dairy Sci. 94:4152-4163.

Bastin, C., H. Soyeurt, and N. Gengler. 2013. Genetic parameters of milk production traits and fatty acid contents in milk for Holstein cows in parity 1-3. J. Anim. Breed. Genet. 130:118-127.

Bauman, D. E., and C. L. Davis. 1973. Biosynthesis of milk fat. Pages 31-75 in Lactation: A Comprehensive Treatise. B. L. Larson and V. R. Smith, ed. Academic Press, New York, NY.

Bauman, D. E., and J. M. Griinari. 2003. Nutritional regulation of milk fat synthesis. Annu. Rev. Nutr. 23:203-227.

Bauman, D. E., and A. L. Lock. 2010. Milk fatty acid composition: Challenges and opportunities related to human health. Pages 278289 in Proc. 26th World Buiatrics Congr. Chilean Buiatric Society, Santiago, Chile.

Bilal, G., R. I. Cue, A. F. Mustafa, and J. F. Hayes. 2014. Short communication: Genetic parameters of individual fatty acids in milk of Canadian Holsteins. J. Dairy Sci. 97:1150-1156.

Bobe, G., J. A. Minick Bormann, G. L. Lindberg, A. E. Freeman, and D. C. Beitz. 2008. Short communication: Estimates of genetic variation of milk fatty acids in US Holstein cows. J. Dairy Sci. 91:1209-1213.

Bonfatti, V., A. Fleming, A. Koeck, and F. Miglior. 2017. Standardization of milk infrared spectra for the retroactive application of calibration models. J. Dairy Sci. 100:2032-2041.

Calo, L. L., R. E. McDowell, L. D. VanVleck, and P. D. Miller. 1973. Genetic aspects of beef production among Holstein-Friesians pedigree selected for milk production. J. Anim. Sci. 37:676-682.

Chilliard, Y., A. Ferlay, and M. Doreau. 2001. Effect of different types of forages, animal fat or marine oils in cow's diet on milk fat secretion and composition, especially conjugated linoleic acid (CLA) and polyunsaturated fatty acids. Livest. Prod. Sci. 70:31-48.

Chilliard, Y., A. Ferlay, R. M. Mansbridge, and M. Doreau. 2000. Ruminant milk plasticity: Nutritional control of saturated, polyunsaturated, trans and conjugated fatty acids. Ann. Zootech. 49:181-205.
Christie, W. W. 1981. The composition, structure and function of lipids in the tissues of ruminant animals. Pages 95-191 in Lipid Metabolism in Ruminant Animals. W. W. Christie, ed. Pergamon Press, Oxford, UK.

Denke, M. A., and S. M. Grundy. 1992. Comparison of effects of lauric acid and palmitic acid on plasma lipids and lipoproteins. Am. J. Clin. Nutr. 56:895-898.

DePeters, E. J., J. F. Medrano, and B. A. Reed. 1995. Fatty acid composition of milk fat from three breeds of dairy cattle. Can. J. Anim. Sci. 75:267-269.

Fleming, A. 2016. Phenotypic and genetic variation of milk fat components incorporating mid-infrared technology. PhD Thesis. Department of Animal Biosciences, University of Guelph, Guelph, Canada.

Garnsworthy, P. C., S. Feng, A. L. Lock, and M. D. Royal. 2010. Short communication: Heritability of milk fatty acid composition and stearoyl-CoA desaturase indices in dairy cows. J. Dairy Sci. 93:1743-1748.

Garnsworthy, P. C., L. L. Masson, A. L. Lock, and T. T. Mottram. 2006. Variation of milk citrate with stage of lactation and de novo fatty acid synthesis in dairy cows. J. Dairy Sci. 89:1604-1612.

Garnsworthy, P. C., and J. H. Topps. 1982. The effect of body condition score at calving on their feed intake and performance when given complete diets. Anim. Prod. 35:113-119.

Gibson, J. P. 1991. The potential for genetic change in milk fat composition. J. Dairy Sci. 74:3258-3266.

Gilmour, A. R., B. J. Gogel, B. R. Cullis, R. Thompson, and D. Butler. 2009. ASReml User Guide Release 3.0. VSN International Ltd., Hemel Hempstead, UK.

Gion, A., H. Larroque, M. Brochard, F. Lahalle, and D. Boichard. 2011. Genetic parameter estimation for milk fatty acids in three French dairy cattle breeds. Interbull Bull. 44:185-189.

Grummer, R. R. 1991. Effect of feed on the composition of milk fat. J. Dairy Sci. 74:3244-3257.

Jamrozik, J., L. R. Schaeffer, and K. A. Weigel. 2002. Estimates of genetic parameters for single-and multiple-country test-day models. J. Dairy Sci. 85:3131-3141.

Jensen, R. G. 2002. The composition of bovine milk lipids: January 1995 to December 2000. J. Dairy Sci. 85:295-350.

Jensen, R. G., A. M. Ferris, and C. J. Lammi-Keefe. 1991. The composition of milk fat. J. Dairy Sci. 74:3228-3243.

Karijord, Ø., N. Standal, and O. Syrstad. 1982. Sources of variation in composition of milk fat. J. Anim. Breeding Genet. 99:81-93.

Kay, J. K., W. J. Weber, C. E. Moore, D. E. Bauman, L. B. Hansen, H. Chester-Jones, B. A. Crooker, and L. H. Baumgard. 2005. Effects of week of lactation and genetic selection for milk yield on milk fatty acid composition in Holstein cows. J. Dairy Sci. 88:3886-3893

Kgwatalala, P. M., E. M. Ibeagha-Awemu, A. F. Mustafa, and X. Zhao. 2009. Stearoyl-CoA desaturase 1 genotype and stage of lactation influences milk fatty acid composition of Canadian Holstein cows. Anim. Genet. 40:609-615.

Lopez-Villalobos, N., R. J. Spelman, J. Melis, S. R. Davis, S. D. Berry, K. Lehnert, S. E. Holroyda, A. K. H. MacGibbon, and R. G. Snell. 2014. Estimation of genetic and crossbreeding parameters of fatty acid concentrations in milk fat predicted by mid-infrared spectroscopy in New Zealand dairy cattle. J. Dairy Res. 81:340-349.

Månsson, H. L. 2008. Fatty acids in bovine milk fat. Food Nutr. Res. 52. https://doi.org/10.3402/fnr.v52i0.1821.

Mele, M., R. Dal Zotto, M. Cassandro, G. Conte, A. Serra, A. Buccioni, G. Bittante, and P. Secchiari. 2009. Genetic parameters for conjugated linoleic acid, selected milk fatty acids, and milk fatty acid unsaturation of Italian Holstein-Friesian cows. J. Dairy Sci. 92:392-400.

Mensink, R. P., P. L. Zock, A. D. Kester, and M. B. Katan. 2003. Effects of dietary fatty acids and carbohydrates on the ratio of serum total to HDL cholesterol and on serum lipids and apolipoproteins: A meta-analysis of 60 controlled trials. Am. J. Clin. Nutr. 77:1146-1155. 
Micha, R., and D. Mozaffarian. 2010. Saturated fat and cardiometabolic risk factors, coronary heart disease, stroke, and diabetes: A fresh look at the evidence. Lipids 45:893-905.

Palmquist, D. L., A. D. Beaulieu, and D. M. Barbano. 1993. Feed and animal factors influencing milk fat composition. J. Dairy Sci. 76:1753-1771.

Penasa, M., F. Tiezzi, P. Gottardo, M. Cassandro, and M. De Marchi. 2015. Short communication: Genetics of milk fatty acid groups predicted during routine data recording in Holstein dairy cattle. Livest. Sci. 173:9-13.

Renner, E., and U. Kosmack. 1974. Genetic aspects concerning fatty acid composition of milk fat. 2. Fatty acid pattern of milk from progeny groups. Zuchtungskunde 46:217-226.

Sauer, F. D., V. Fellner, R. Kinsman, J. K. G. Kramer, H. A. Jackson, A. J. Lee, and S. Chen. 1998. Methane output and lactation response in Holstein cattle with monensin or unsaturated fat added to the diet. J. Anim. Sci. 76:906-914.

Soyeurt, H., P. Dardenne, F. Dehareng, C. Bastin, and N. Gengler. 2008a. Genetic parameters of saturated and monounsaturated fatty acid content and the ratio of saturated to unsaturated fatty acids in bovine milk. J. Dairy Sci. 91:3611-3626.

Soyeurt, H., P. Dardenne, F. Dehareng, G. Lognay, D. Veselko, M. Marlier, C. Bertozzi, P. Mayeres, and N. Gengler. 2006a. Estimating fatty acid content in cow milk using mid-infrared spectrometry. J. Dairy Sci. 89:3690-3695.

Soyeurt, H., P. Dardenne, A. Gillon, C. Croquet, S. Vanderick, P. Mayeres, N. Bertozzi, and N. Gengler. 2006b. Variation in fatty acid contents of milk and milk fat within and across breeds. J Dairy Sci. 89:4858-4865.

Soyeurt, H., F. Dehareng, C. Bertozzi, and N. Gengler. 2007a. Genetic parameters of butter hardness estimated by test-day model. Interbull Bull. 37:49-53.

Soyeurt, H., F. Dehareng, P. Mayeres, C. Bertozzi, and N. Gengler. 2008b. Variation of $\Delta^{9}$-desaturase activity in dairy cattle. J. Dairy Sci. 91:3211-3224.

Soyeurt, H., A. Gillon, S. Vanderick, P. Mayeres, C. Bertozzi, and N. Gengler. 2007b. Estimation of heritability and genetic correlations for the major fatty acids in bovine milk. J. Dairy Sci. 90:4435-4442.

Spiegelhalter, D. J., N. G. Best, B. P. Carlin, and A. Van Der Linde. 2002. Bayesian measures of model complexity and fit. J. R. Stat. Soc. B 64:583-639.

Stoop, W. M., J. A. M. Van Arendonk, J. M. L. Heck, H. J. F. Van Valenberg, and H. Bovenhuis. 2008. Genetic parameters for major milk fatty acids and milk production traits of Dutch HolsteinFriesians. J. Dairy Sci. 91:385-394.

Temme, E. H., R. P. Mensink, and G. Hornstra. 1996. Comparison of the effects of diets enriched in lauric, palmitic, or oleic acids on serum lipids and lipoproteins in healthy women and men. Am. J. Clin. Nutr. 63:897-903.

Zock, P. L., J. H. De Vries, and M. B. Katan. 1994. Impact of myristic acid versus palmitic acid on serum lipid and lipoprotein levels in healthy women and men. Arterioscler. Thromb. 14:567-575.

\section{APPENDIX}

Table A1. Average daily permanent environmental correlations (above the diagonal) ${ }^{1}$ and average daily herdyear of calving effect correlations (below the diagonal) ${ }^{2}$ for fatty acid groups in first-lactation Holstein cows

\begin{tabular}{lccccc}
\hline Fatty acid & $\begin{array}{c}\text { Short- } \\
\text { chain }\end{array}$ & $\begin{array}{c}\text { Medium- } \\
\text { chain }\end{array}$ & $\begin{array}{c}\text { Long- } \\
\text { chain }\end{array}$ & Saturated & Unsaturated \\
\hline $\begin{array}{l}\text { Short-chain } \\
\text { Medium-chain }\end{array}$ & 0.24 & 0.81 & 0.60 & 0.85 & 0.51 \\
Long-chain & 0.10 & 0.15 & & 0.95 & 0.58 \\
Saturated & 0.28 & 0.48 & 0.22 & 0.83 \\
Unsaturated & 0.07 & 0.14 & 0.34 & 0.16 & 0.60 \\
\hline
\end{tabular}

${ }^{1}$ Posterior SD ranged from 0 to 0.001 .

${ }^{2}$ Posterior SD ranged from 0.003 to 0.005 .

Table A2. Average daily residual correlations for fatty acid groups in first-lactation Holstein cows

\begin{tabular}{lcccc}
\hline Fatty acid & Medium-chain & Long-chain & Saturated & Unsaturated \\
\hline Short-chain & 0.67 & 0.40 & 0.69 & 0.36 \\
Medium-chain & & 0.43 & 0.84 & 0.43 \\
Long-chain & & 0.56 & 0.83 \\
Saturated & & & 0.52 \\
\hline
\end{tabular}




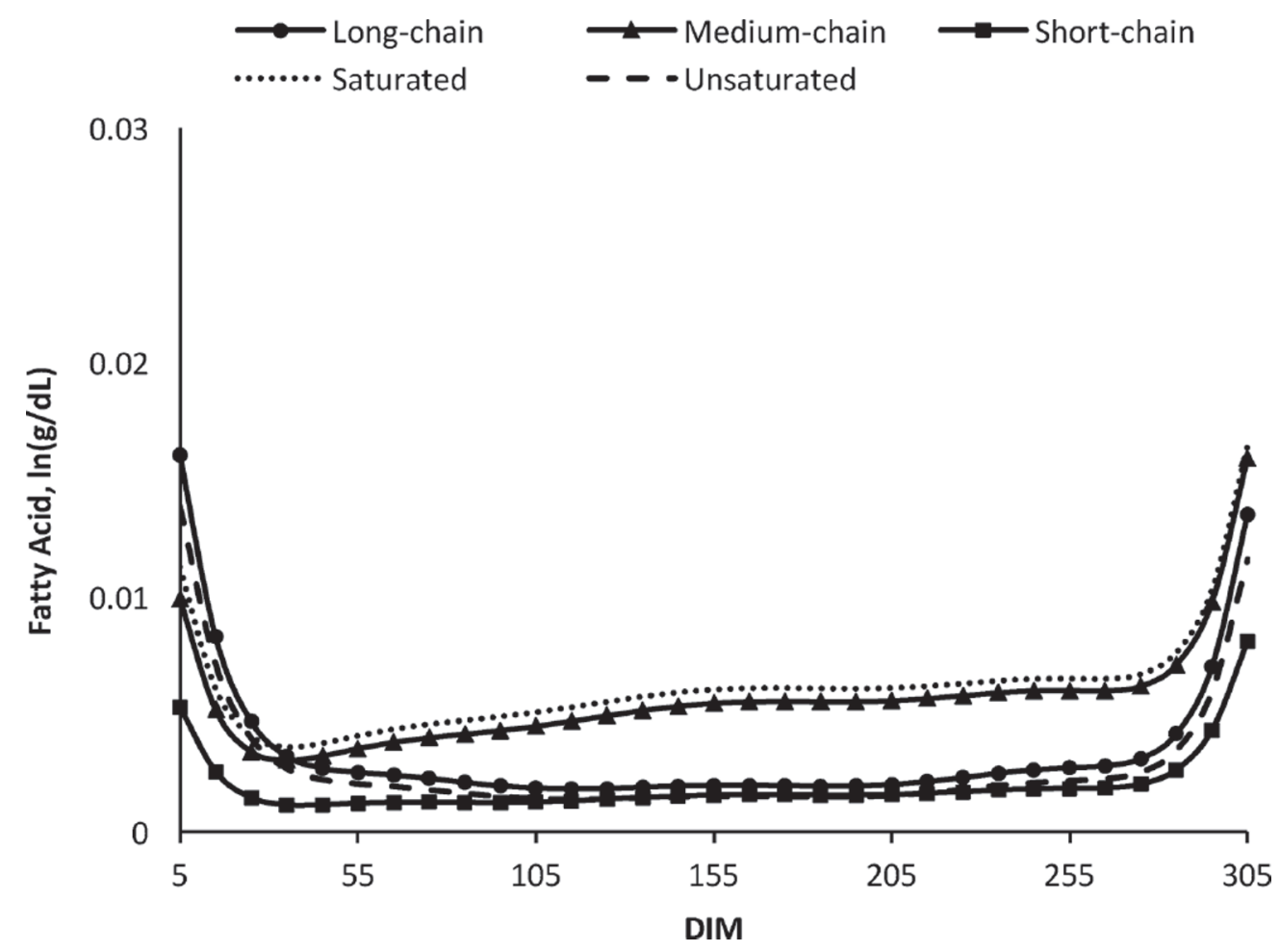

Figure A1. Additive genetic variances over the lactation for long-chain, medium-chain, short-chain, saturated, and unsaturated fatty acid groups in first-lactation Holstein cows.

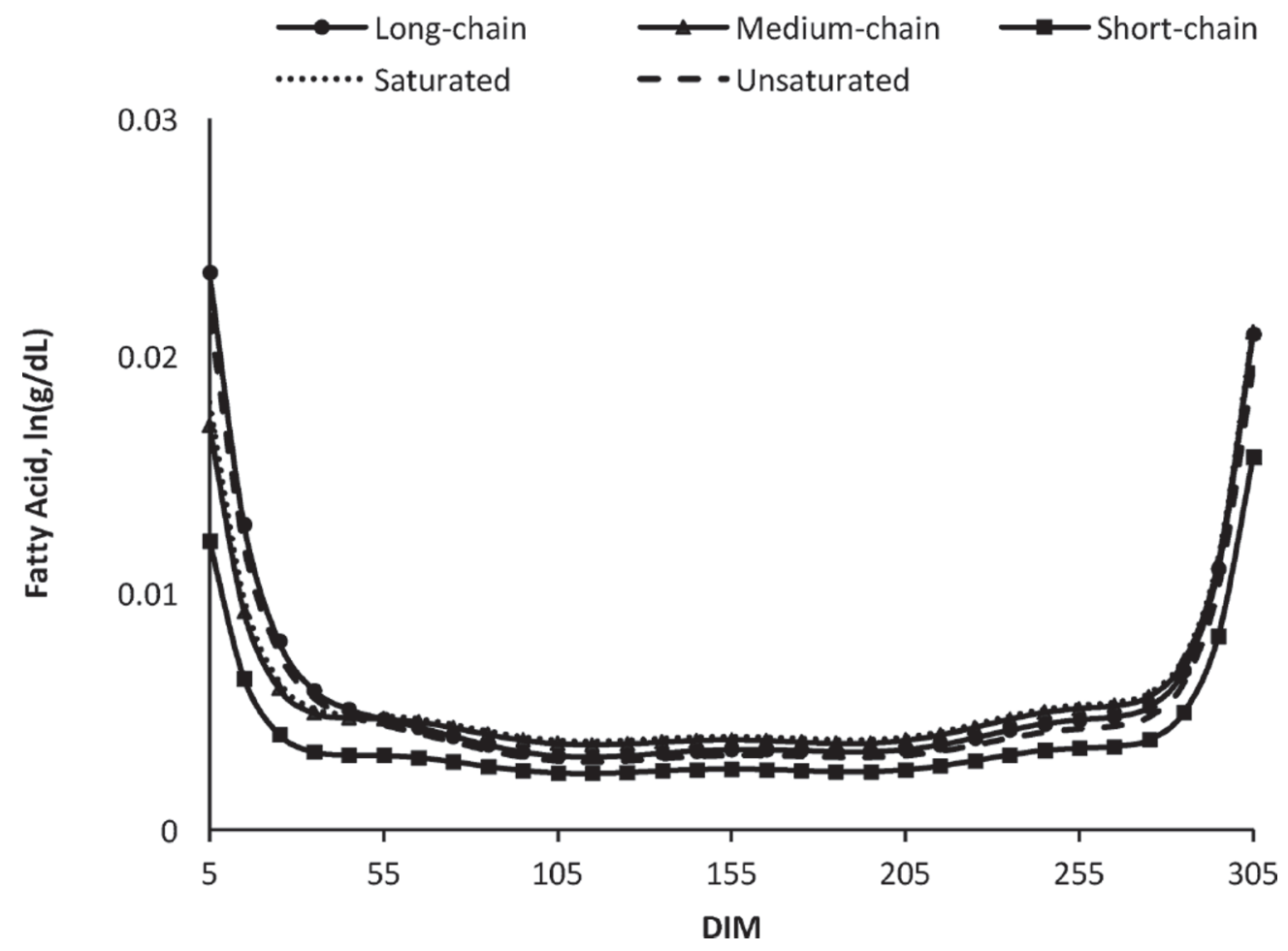

Figure A2. Herd-year of calving variances over the lactation for long-chain, medium-chain, short-chain, saturated, and unsaturated fatty acid groups in first-lactation Holstein cows. 


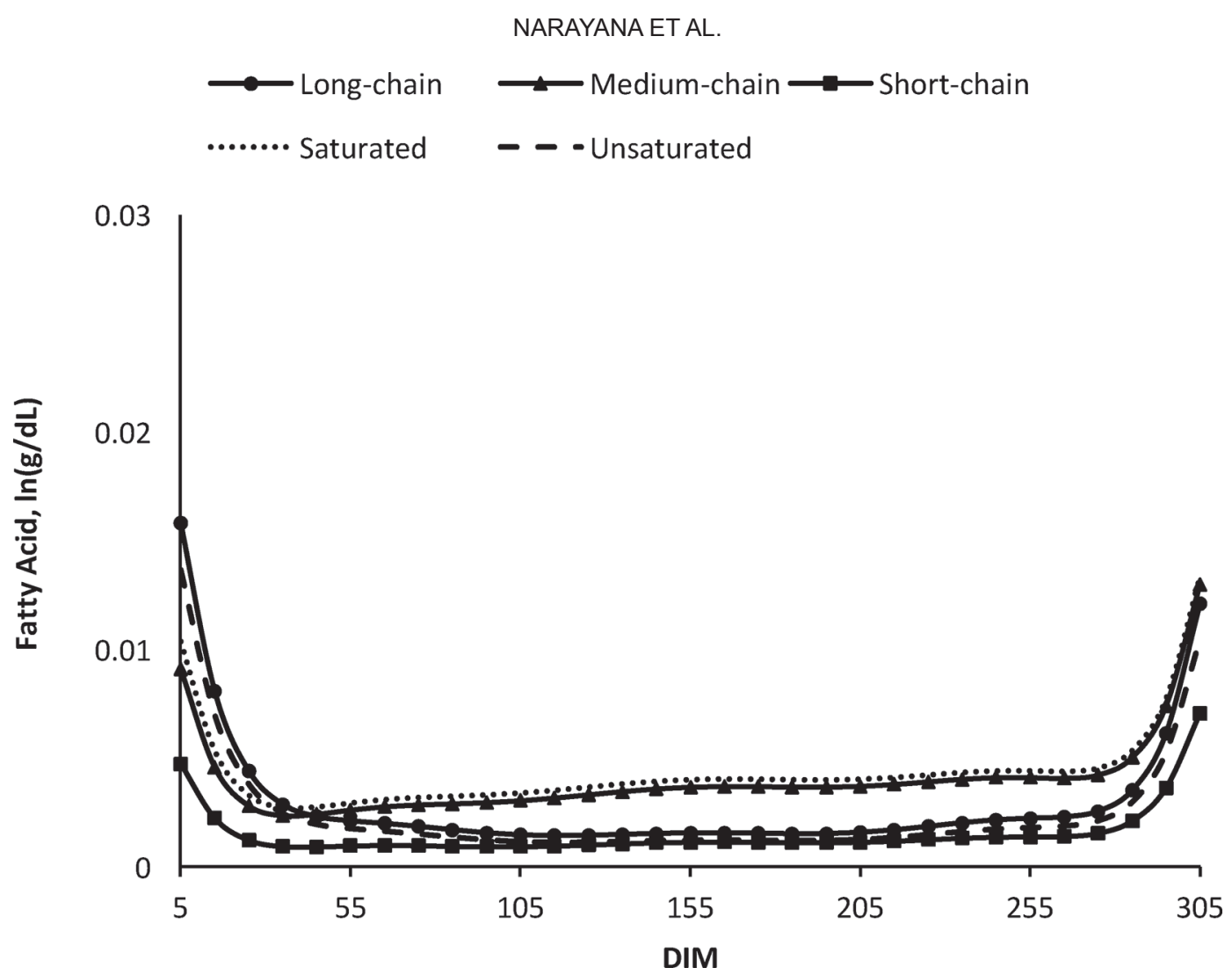

Figure A3. Permanent environmental variances over the lactation for long-chain, medium-chain, short-chain, saturated, and unsaturated fatty acids in first-lactation Holstein cows. 